\title{
Rapid assessment of avoidable blindness in the northern eThekwini district of KwaZulu-Natal Province, South Africa
}

\begin{abstract}
Authors:
Pirindhavellie Govender ${ }^{1,2}$

Prasidh Ramson ${ }^{1}$

Linda Visser ${ }^{3}$

Kovin S. Naidoo ${ }^{1,2}$

Affiliations:

${ }^{1}$ Brien Holden Vision

Institute, Durban,

South Africa

${ }^{2}$ African Vision Research Institute, University of KwaZulu-Natal, South Africa

${ }^{3}$ University of KwaZulu-Natal, Durban, South Africa

Correspondence to: Pirindhavellie Govender

Email:

p.govender@

brienholdenvision.org.za

Postal address:

Brien Holden Vision Institute,

172 Umbilo Road, Durban

4001, South Africa

\section{Dates:}

Received: 22 Jan. 2014

Accepted: 12 Dec. 2014

Published: 12 June 2015

How to cite this article: Govender P, Ramson P, Visser L, Naidoo KS. Rapid assessment of avoidable blindness in the northern eThekwini district of KwaZulu-Natal Province, South Africa. Afr Vision Eye Health. 2015;74(1), Art. \#15, 7 pages. http://dx.doi. org/10.4102/aveh.v74i1.15

\section{Copyright:}

C 2015. The Author(s).

Licensee: AOSIS

OpenJournals. This work is licensed under the Creative Commons Attribution License.
\end{abstract}

\section{Read online:}

Aim: To determine the prevalence and causes of visual impairment, cataract surgical coverage and barriers to cataract surgery amongst people in the northern eThekwini district of KwaZuluNatal Province, South Africa.

Method: Thirty-three clusters of 50 subjects $\geq 50$ years old were randomly selected. Consenting subjects underwent enumeration to establish a demographic profile and thereafter a clinical examination. Visual acuity (VA) was measured with a Tumbling ' $\mathrm{E}^{\prime}$ chart; participants having a VA $<6 / 18$ were retested with a pinhole. If no improvement in VA occurred, subjects underwent clinical examination, including a dilated fundus exam where necessary, to determine the cause of visual impairment.

Results: Of the 1650 subjects selected, 1542 (93.5\%) were examined. The overall prevalence of blindness was $1.9 \%$. The age- and gender-adjusted prevalence of blindness was $2.1 \%$, severe visual impairment (SVI) $1.2 \%$, and moderate visual impairment (MVI) $3.9 \%$. Untreated cataract was the major cause of blindness $(55.2 \%)$ and SVI $(53.3 \%)$, and uncorrected refractive error was the major cause of MVI (49.1\%). The cataract surgical coverage rate was $70 \%$ at visual acuity $<3 / 60$ level; $51 \%$ at visual acuity $<6 / 60$ level; and $38 \%$ at visual acuity $<6 / 18$ level. Poor awareness of cataract surgical intervention was the main reason that participants with untreated cataracts had not used existing cataract services.

Conclusion: The prevalence of blindness in the study region was lower (by 1.98\%) than World Health Organization estimates of $9 \%$ for the Africa-E sub-region (within which South Africa falls). There is no permanent cataract service in this region; the lower cataract surgical coverage rates indicate that a permanent eye care centre could significantly alleviate avoidable blindness, particularly that caused by cataract.

\section{Introduction}

Globally, more than $82 \%$ of all blindness occurs in people $\geq 50$ years old. ${ }^{1}$ In Africa, the prevalence is 7.3 blind people per million population. ${ }^{1}$ These estimates are based on the World Health Organization (WHO) definition of blindness as presenting visual acuity (VA) less than 3/60 in the better eye and visual impairment as VA less than $6 / 18$ but at least $3 / 60$ in the better eye. ${ }^{2}$ The study area is in the Africa-E WHO sub-region. ${ }^{3}$ Resnikoff et al. ${ }^{4}$ posit an expected Africa-E subregional prevalence of bilateral blindness in individuals $\geq 50$ years old of $9 \%$.

The implementation of the 'VISION 2020: Right to Sight' campaign has created global awareness of the causes of avoidable blindness and also the need to provide evidence for eye health needs and the impact of interventions to guide future eye health strategies. This awareness has led to an expansion of epidemiological investigations as baseline data became more important. However, according to the International Centre for Eye Health, 'Blindness surveys are usually lengthy, costly and complicated exercises, requiring expert assistance from epidemiologists or statisticians to produce reports. ${ }^{5}$ It is for this reason that surveys have been undertaken in only a few countries and with only a few repeat surveys to determine the effect of the intervention programmes implemented. Comprehensive blindness surveys are therefore often not feasible for planning and monitoring VISION 2020 programmes. Affordable and faster methodologies are required.

The rapid assessment of avoidable blindness (RAAB) methodology has addressed this need. The RAAB study methodology elicits information on the magnitude and causes of blindness and vision impairment via reduced vision screening and ocular health screening of adults $\geq 50$ years old. In addition, this methodology provides information on the output and quality 
of eye care services, barriers to service, cataract surgical coverage and other indicators of eye care services in the study area. Numerous RAAB studies have been conducted in many countries around the world. $6,7,8,9,10,11,12,13$ The RAAB survey provides a needs assessment in the region under investigation so that a focused district plan can be developed or adjusted accordingly.

\section{Blindness and low vision in KwaZulu-Natal}

KwaZulu-Natal (KZN) is one of nine South African provinces and is located in eastern South Africa. It comprises about 10.45 million people, which is $21.2 \%$ of the country's population. ${ }^{14}$ Approximately $15 \%$ of the population is over 50 years old. ${ }^{14}$ The delivery of health services is challenging because $43 \%$ of the population in South Africa live in rural areas. ${ }^{15}$ Previous population-based studies in KZN include the Refractive Error Study in Children in Africa (RESCA) which investigated the prevalence of refractive error in children between 5 and 15 years old, ${ }^{16}$ the presbyopia study ${ }^{17}$ and the rapid assessment of refractive error (RARE) study, as mentioned by lead researcher Professor Kovin Naidoo (personal communication with Professor Naidoo, 12 September 2011).

The aim of the present study was to determine the prevalence, causes of visual impairment, cataract surgical coverage and barriers to cataract surgery amongst people in the northern eThekwini district of KwaZulu-Natal Province, South Africa.

\section{Methods}

\section{Sample selection}

The RAAB study area specifically comprised Inanda, Ntuzuma, KwaMashu, Amaoti and Phoenix - disadvantaged communities during the apartheid era. The total population in the area was 849817 , with a mixture of urban, periurban and semi-rural areas. ${ }^{14}$ As in the rest of South Africa, the delivery of eye care follows the district health model. Current eye care infrastructure in the study area comprises one district hospital, one private hospital, four community health clinics and several private optometry practices. According to Mashige et al., ${ }^{18}$ human resources for eye health in the area were one part-time ophthalmologist, one full-time optometrist based at the district hospital, two ophthalmic nurses, several locum optometrists providing services on a sessional basis, and several optometrists in the private sector. The full-time optometrist was employed just prior to conducting the study. Primary community centres in the area refer to community health centres supported by non-government organisation (NGO)-based optometrists; however, services were only provided on a part-time basis.

The $9 \%$ estimated sub-regional prevalence of bilateral blindness in individuals $\geq 50$ years old was used in the calculation of the sample size. Additional factors taken into consideration in determining the sample size included the precision of $20 \%$ of the estimate (i.e. the worst acceptable result of $7.8 \%$ ), a design effect (DEFF) of 1.5 , a confidence interval $(\mathrm{CI})$ of $95 \%$ and a non-compliance rate of $10 \%$. The final sample size was automatically computed by the RAAB software package (available at http:/ /www.cehjournal.org/ resources/raab/). The calculation of sample size is given by the equation below:

$\mathrm{S}_{\text {infinite population }}=[\mathrm{Z} * \mathrm{Z}(\mathrm{P}(1-\mathrm{P})) / \mathrm{D} * \mathrm{D}]$

[Eqn 1]

where $\mathrm{S}$ is the sample size for simple random sampling, $\mathrm{P}$ is the expected prevalence of the condition $(9 \%), \mathrm{D}$ is half the width of the desired sample $\mathrm{CI}(0.2)$, and $\mathrm{Z}$ is the percentile of the standard normal distribution, determined by the specified CI level (1.96 for 95\% CI). Multiplying S x DEFF provides the resultant sample size that determined the number of groups of 50 people in each cluster. Thirty-three clusters or groups were thus selected in the study area.

\section{Enumeration and recruitment of study participants}

Cluster random sampling using census data was used to select the specific enumerated areas (EAs) from the total population. Geographical Information System (GIS) maps were used to divide each EA into clearly demarcated segments (clusters) of equal population so that the cluster size and number of clusters could be determined. Each household within the selected clusters was visited until 50 people $\geq 50$ years old were enumerated. Eligible subjects were those individuals $\geq 50$ years old and who lived in a household for $\geq 6$ months. The interviews and clinical examinations of these individuals were done by the survey team. The survey team (as recommended by the RAAB protocol) comprised an ophthalmologist, an optometrist and enumerators, and was led daily by a local community person to perform door-todoor household visits. Eligible subjects who were not at home at the time of the visit were revisited a day later. If the subject was still not available for examination after three visits, information on visual status was collected from reports of a relative or neighbour. The surrogate response was classified as either not blind, blind owing to cataract, blind owing to other cause, and operated for cataract.

\section{Ethical approval}

Ethical approval for the study was granted by the University of KwaZulu-Natal's Biomedical Research and Ethics Committee (BREC) and the Provincial Department of Health's Health Research and Knowledge Management unit. Permission was also obtained from the local council and management structures to conduct the study in the selected study area. All subjects in the study were examined after informed consent and information documents were signed. All individuals requiring further investigation for refractive correction, treatment of ocular disease or further investigative procedures were referred to the most appropriate and accessible eye care facilities. Findings from the research were disseminated to the community in a feedback session to the community and its leaders at the end of the study. 


\section{Training}

The study was preceded by a training session and pilot study involving the enumerators and clinical team to ensure the ability of all individuals in the study to carry out their respective roles. Kappa values were used as a measure of inter-observer agreement between the clinical research team and a 'gold standard' team, with 0.6 being an acceptable standard. All clinicians satisfied this criterion.

\section{Clinical examination}

The standardised RAAB protocol was used in the clinical examination and involved the assessment of visual acuity using a tumbling E optotype of 6/60 and 6/18 sizes. Subjects who failed testing on the $6 / 60$ optotype target were retested with a pinhole occluder. Blindness was classified as VA $<3 / 60$ in the better eye with available correction; severe visual impairment as VA between $\geq 3 / 60$ and $6 / 60$ in the better eye with available correction; and moderate visual impairment as VA between $\geq 6 / 60$ and $6 / 18$ in the better eye with available correction. The VA examination was followed by an examination of the crystalline lens and the posterior segment with a direct ophthalmoscope. Subjects presenting with $\mathrm{VA}<6 / 18$ and with no improvement with pinhole were dilated using $0.5 \%$ tropicamide solution, and a dilated ophthalmoscopy was performed to determine any posterior segment cause for vision impairment. A questionnaire on the barriers to cataract surgery and surgical success was administered to subjects presenting with cataracts or who had undergone cataract surgery respectively.

\section{Statistical analysis}

The specific RAAB software package developed for the survey (Version 4.02) was used for data entry and standardised data analysis. ${ }^{4}$ Data were captured by double entry (to ensure reliability of data entry) and reports were generated daily to ensure consistency within the data capture process. Automated analyses produced reports on the unadjusted prevalence of visual impairment, causes of visual impairment, age- and gender-adjusted prevalence, and cataract surgical coverage. Multiple logistic regression analysis was conducted to determine associations between gender, age and education levels and various degrees of vision loss.

The survey was carried out over 6 weeks from October to November 2009.

\section{Results}

\section{Demographics of the sample}

A total of 1650 individuals was selected, with a $93.5 \%$ response rate. A small percentage $(0.4 \%)$ of individuals were not available for examination and a surrogate response was documented; a similar percentage of individuals were not capable of having an examination; and $5.7 \%$ refused to be examined. The median age of all examined subjects was 60 years (inter-quartile range [IQR] 54-68 years). Women constituted $68.8 \%$ of selected individuals and $70 \%$ of examined individuals of the total study sample. The majority of the sample (86.0\%) were black people, $9.4 \%$ were Indian and $4.6 \%$ were of mixed heritage. The age and gender composition of examined participants in relation to the population in the survey area is summarised in Table 1.

\section{Bilateral vision loss in the sample}

The prevalence of bilateral blindness, SVI and VI is summarised in Table 2.

The age- and gender- adjusted prevalence of blindness in all examined individuals was $1.9 \%$ (95\% CI: $1.2-2.6)$. The prevalence of bilateral SVI was lower (1.0\% [95\% CI: 0.5-1.5]) while VI was higher at 3.6\% (95\% CI: 2.6-4.5).

\section{Causes of vision loss in the sample}

Cataract was the major cause of bilateral blindness (55.2\%) and SVI (53.3\%) whilst refractive error was the major cause of

TABLE 1: Age and gender composition of examined participants in relation to the population in the survey area.

\begin{tabular}{|c|c|c|c|c|c|c|c|c|}
\hline \multirow[t]{3}{*}{ Age groups (years) } & \multicolumn{4}{|c|}{ Men } & \multicolumn{4}{|c|}{ Women } \\
\hline & \multicolumn{2}{|c|}{ Sample } & \multicolumn{2}{|c|}{ Population } & \multicolumn{2}{|c|}{ Sample } & \multicolumn{2}{|c|}{ Population } \\
\hline & $n$ & $\%$ & $n$ & $\%$ & $n$ & $\%$ & $n$ & $\%$ \\
\hline $50-59$ & 230 & 49.7 & 276400 & 52.7 & 495 & 45.9 & 378000 & 47.6 \\
\hline $60-69$ & 163 & 35.2 & 168200 & 32.1 & 309 & 28.6 & 248300 & 31.3 \\
\hline 70-79 & 55 & 11.9 & 64900 & 12.4 & 188 & 17.4 & 127100 & 16.0 \\
\hline $80+$ & 15 & 3.2 & 14500 & 2.8 & 86 & 8.0 & - & - \\
\hline Not stated & 0 & 0.0 & - & - & 1 & 0.1 & 40300 & 5.1 \\
\hline Total & 463 & 100 & 524000 & 100 & 1079 & 100 & 793700 & 100 \\
\hline
\end{tabular}

TABLE 2: Distribution by presenting visual acuity (with available correction) in the better eye (before pinhole examination).

\begin{tabular}{|c|c|c|c|c|c|c|c|c|c|}
\hline \multirow[t]{2}{*}{ VA with available correction } & \multicolumn{3}{|c|}{ Men $(n=463)$} & \multicolumn{3}{|c|}{ Women $(n=1079)$} & \multicolumn{3}{|c|}{ Total $(N=1542)$} \\
\hline & $n$ & Prevalence & $95 \% \mathrm{Cl}$ & $n$ & Prevalence & $95 \% \mathrm{Cl}$ & $n$ & Prevalence & $95 \% \mathrm{Cl}$ \\
\hline $\mathrm{VA}<3 / 60$, bilateral blindness & 11 & 2.4 & $1.6-3.1$ & 18 & 1.7 & $1.0-2.3$ & 29 & 1.9 & $1.2-2.6$ \\
\hline VA $<6 / 60$ and $\geq 3 / 60$, bilateral SVI & 4 & 0.9 & $0.4-1.3$ & 11 & 1.0 & $0.5-1.5$ & 15 & 1.0 & $0.5-1.5$ \\
\hline $\mathrm{VA}<6 / 18$ and $\geq 6 / 60$, bilateral MVI & 13 & 2.8 & $2.0-3.6$ & 42 & 3.9 & $2.9-4.9$ & 55 & 3.6 & $2.6-4.5$ \\
\hline
\end{tabular}

VA, visual acuity; SVI, severe visual impairment; MVI, moderate visual impairment. 
TABLE 3: Causes of visual loss (with available correction) in the study sample.

\begin{tabular}{|c|c|c|c|c|c|c|}
\hline \multirow[t]{2}{*}{ Cause of vision loss } & \multicolumn{2}{|c|}{ Bilateral blindness } & \multicolumn{2}{|c|}{ Bilateral severe visual impairment } & \multicolumn{2}{|c|}{ Bilateral moderate visual impairment } \\
\hline & $n$ & $\mathrm{VA}<3 / 60(\%)$ & $n$ & $V A<6 / 60-\geq 3 / 60(\%)$ & $n$ & $V A<6 / 18-\geq 6 / 60(\%)$ \\
\hline Refractive error & 2 & 6.9 & 2 & 13.3 & 27 & 49.1 \\
\hline Cataract & 16 & 55.2 & 8 & 53.3 & 20 & 36.4 \\
\hline Surgical complications & 0 & - & 0 & - & 1 & 1.8 \\
\hline Corneal scar & 1 & 3.4 & 0 & - & 0 & - \\
\hline Glaucoma & 7 & 24.1 & 1 & 6.7 & 3 & 5.5 \\
\hline Diabetic retinopathy & 2 & 6.9 & 3 & 20.0 & 2 & 3.6 \\
\hline Other posterior segment disease & 1 & 3.4 & 1 & 6.7 & 2 & 3.6 \\
\hline Total & 29 & 100 & 15 & 100 & 55 & 100 \\
\hline
\end{tabular}

Note: Causes of visual loss (with available correction) in the study sample were determined by vision loss in the better eye. Total avoidable vision loss was a combination of total curable and total preventable vision loss.

$\mathrm{VA}$, visual acuity.

TABLE 4: Associations between age, gender and education, and vision loss.

\begin{tabular}{|c|c|c|c|c|c|c|c|c|c|c|}
\hline \multirow{2}{*}{$\begin{array}{l}\text { Demographic } \\
\text { factor }\end{array}$} & \multirow[t]{2}{*}{ Demographic variables } & \multicolumn{3}{|c|}{ Blindness } & \multicolumn{3}{|c|}{ Severe visual impairment } & \multicolumn{3}{|c|}{ Visual impairment } \\
\hline & & OR & $95 \% \mathrm{Cl}$ & $p$-value & OR & $95 \% \mathrm{Cl}$ & $p$-value & OR & $95 \% \mathrm{Cl}$ & $p$-value \\
\hline Gender & Female & 0.5 & $0.2-0.9$ & 0.028 & 1.4 & $0.4-4.6$ & 0.612 & 1.2 & $0.6-2.4$ & 0.676 \\
\hline \multirow[t]{3}{*}{ Age group } & $60-69$ years & 2.3 & $0.6-8.9$ & 0.222 & 0.5 & $0.1-3.0$ & 0.443 & 2.0 & $0.9-4.4$ & 0.069 \\
\hline & 70-79 years & 9.7 & $2.9-32.9$ & 0.001 & 2.0 & $0.6-7.0$ & 0.248 & 2.9 & $1.3-6.5$ & 0.012 \\
\hline & $\geq 80$ years & 15.3 & $4.1-57.2$ & 0 & 2.3 & $0.3-15.5$ & 0.381 & 5.2 & $2.2-12.6$ & 0.001 \\
\hline \multirow[t]{4}{*}{ Education } & Primary school incomplete & 1.5 & $0.6-3.8$ & 0.409 & 2.1 & $0.6-7.5$ & 0.256 & 0.7 & $0.3-1.6$ & 0.343 \\
\hline & Primary school complete & 0.4 & $0.9-1.5$ & 0.152 & 0.8 & $0.1-6.7$ & 0.819 & 0.7 & $0.3-1.9$ & 0.466 \\
\hline & Secondary school incomplete & 0.5 & $0.1-2.5$ & 0.411 & 0.5 & $0.0-6.6$ & 0.617 & 0.3 & $0.1-1.1$ & 0.072 \\
\hline & Secondary school or higher complete & 0.6 & $0.1-3.0$ & 0.551 & 0.9 & $0.1-8.8$ & 0.911 & 0.5 & $0.1-2.1$ & 0.29 \\
\hline
\end{tabular}

moderate visual impairment (49.1\%) (Table 3). Glaucoma was the second leading cause of blindness (24.1\%) whilst diabetic retinopathy was the second leading cause of severe vision impairment $(20.0 \%)$, and cataract the second leading cause of moderate vision impairment (36.4\%).

\section{Cataract blindness, surgical outcomes and cataract surgical coverage}

Cataracts produced bilateral blindness in $0.7 \%$ of the total sample; $61.5 \%$ of participants were bilaterally blind and $54.0 \%$ of participants with unilateral blindness owing to untreated cataracts reported 'unaware of treatment' as the reason for not seeking treatment. Of those subjects who had had cataract surgery, all had intraocular lens implants. The prevalence of pseudophakic eyes was $1.5 \%$ in men, $1.6 \%$ in women, and $1.6 \%$ in the total sample. The majority $(73.5 \%)$ of these cataract surgeries were performed in government hospitals. The majority $(77.8 \%)$ of patients seen in government hospitals presented with post-cataract vision better than or equal to VA of 6/18 (no visual impairment), $8.3 \%$ presented with SVI, and $13.9 \%$ presented with blindness with available correction. All of the patients who were operated on in the private sector presented with no visual impairment. The good cataract outcomes amongst patients in both the private and public sectors corresponded with an $87.8 \%$ satisfaction with the results of the cataract surgery. The VA results of the patients who were operated on revealed that $8.1 \%$ (or four eyes) of the total number of eyes operated on would benefit from having an updated prescription following refraction.

Cataract surgical coverage (CSC) was reflected in the number of aphakic/pseudophakic people divided by the number who had operable cataract (i.e. the number of aphakic/pseudophakic plus the number needing surgery). The CSC was $70.0 \%$ at visual acuity $<3 / 60$ level; $51 \%$ at visual acuity $<6 / 60$ level, and $38 \%$ at visual acuity $<6 / 18$ level. Overall, CSC was greater amongst women than men.

Multiple logistic regression analysis was performed to determine associations between vision loss and age, gender and level of education (Table 4). A significant association was found between blindness and females (odds ratio [OR] 0.45 ; 95\% CI: $0.22-0.91 ; p=0.028)$ where women had a lower chance of being blind, whilst 70-79-year-olds (OR 9.72; 95\% CI: 2.87-32.90; $p=0.001$ ) and individuals $>80$ years old (OR 15.27; 95\% CI: 4.07-57.29; $p=0.000$ ) showed a greater probability of being blind than 50-59-year-olds. Significant strong associations were found between visual impairment and individuals between 70 and 79 years old (OR 2.87; 95\% CI: $1.28-6.46 ; p=0.012$ ) and $>80$ years old (OR 5.21; 95\% CI: $2.16-12.57 ; p=0.001$ ). In contrast, no significant associations were found between severe visual impairment and age, gender and level of education. Participants $>70$ years old showed 2.9 times higher odds (95\% CI: $1.3-6.5 ; p=0.012$ ) of presenting with VI than individuals who were $50-59$ years old.

\section{Discussion}

The high percentage of women in the study area and the sample may be because of a number of reasons including level of unemployment and the mobility and migration of male workers to other areas. The scope of the study did not lend to an explanation of the reasons for refusal of the clinical examination. The data gathered in this study revealed a 
fairly low prevalence of blindness of $2.1 \%$ (95\% CI: 1.3-2.8). All RAAB studies in the eastern region of Africa revealed similar findings. ${ }^{6,8,19,20,21,22,23}$ Whilst the overall prevalence of blindness was comparatively low in the present study, it is important to note that there was a paucity of full-time human resources to address the visual demands of the study area, which indicated that the problem that existed was significant. The Provincial Department of Health has since employed more full-time staff, and further support has been lent by NGOs.

By extrapolation of prevalence data obtained for the age and gender distribution in people $\geq 50$ years old in the study area, it can be estimated that 2673 men and 3390 women are blind, 1374 men and 1776 women are severely visually impaired, and 8633 men and 7832 women are visually impaired. The visual acuity cut-off of $6 / 18$ in the RAAB studies is not reflective of the challenges faced by all individuals with visual impairment. The cut-off is set to ensure that resource-limited communities can address the most critical cases of vision impairment. However, clinical experience indicates that many individuals find it difficult to function with $6 / 18 \mathrm{VA}$, especially if their work situation demands better acuity, and the problem of visual impairment may be underestimated through the RAAB process. Studies have emphasised the link between vision impairment, and employment and poverty..$^{24,25,26}$

The prevalence of blindness in the study sample was higher amongst men than in women, unlike RAAB studies in Cameroon $^{7}$ and Western Rwanda. ${ }^{20}$ Multivariate analysis of gender and blindness showed that women were 0.45 times less likely to be blind than men (95\% CI: 0.22-0.91; $p=0.028$ ). A meta-analysis conducted by Abou-Gareeb et al. ${ }^{27}$ found that women bore almost two-thirds of the burden of blindness in comparison with men. Previous studies have offered various explanations for women having a greater tendency to be blind than men. However, the literature has offered no explanation for the reverse scenario found in this study. It is recommended that further investigation be conducted to explore gender-related differences in the burden of blindness and vision impairment.

Multivariate analyses showed significant associations between blindness and visual impairment and older age (> 70 years). Saw et al. $^{28}$ cited 'increased prevalence rate of age-related eye disease and poor access to health care among the elderly' as possible reasons for the associated high prevalence of blindness and increasing age. With the exception of this study and the RAAB study in Burundi, all other studies in the East-African sub-region found that cataract was the leading cause of visual impairment in their samples. Our study found that uncorrected refractive error was the primary cause of visual impairment in the sample. The study methodology did not allow for classification of the specific types of refractive error or its magnitude. However, it is possible in this older age group that the myopic shift induced by age-related nuclear sclerosis could be a reason for the higher prevalence of vision impairment owing to refractive error. ${ }^{29}$

In keeping with Pascolini and Mariotti, ${ }^{1}$ the present study found that more than half of the causes of blindness was attributed to cataracts. According to Naidoo, ${ }^{30}$ a high prevalence of preventable causes of blindness could be attributed to a lack of education (knowledge of the condition); this was evident in the study findings as $61 \%$ of subjects with blindness owing to bilateral cataracts did not seek intervention because they were 'unaware of treatment'. This finding suggests the need for health promotion and health education strategies to increase uptake of services.

The relatively high cataract surgical coverage may be a reflection of better existing services in the public sector in South Africa, with the catchment area having a major hospital that provides cataract services, and the cataract services in central Durban are easily accessible by public transport. The cataract surgical coverage was similar to that of Tanzania $(68.9 \%)^{19}$ whilst it was slightly lower than that of Kenya (78\%). ${ }^{22}$ Other countries such as Malawi $(44.6 \%)^{8}$ and Eritrea $(40.8 \%)^{6}$ showed lower cataract surgical coverage. Unlike other studies where men were able to access cataract services more readily than women, our study revealed higher cataract surgical coverage amongst women than men. ${ }^{6,8,19}$

Unlike other RAAB studies in Africa where gender disparities in access to cataract surgery was evident, ${ }^{8,23}$ our study and the RAAB study in Kenya ${ }^{22}$ found similar access to cataract services amongst men and women. This finding suggests that there was a reasonable uptake of cataract services within the study area which is a geographically contiguous part of eThekwini Municipality, consisting of urban and semi-urban areas. However, the uptake of cataract services in the study area could differ from that in a rural setting.

Good visual outcomes were observed in eyes operated on less than 5 years ago, which could be attributed to the public sector policy to use intraocular lenses (IOLs) for all cataract surgeries as well as the use of newer procedures such as small incision cataract surgery (SICS) and phacoemulsification which tend to produce better visual outcomes. ${ }^{31}$ In those eyes operated on within the last 5 years of the study, four eyes $(8.2 \%)$ could benefit from an upgrade in their refractive correction. This finding highlights the need for regular follow-up of patients and modification of prescriptions when required. The difference in quality of surgical outcomes between the public and private sectors should not be taken at face value and warrants further investigation. The higher number of surgeries in the public sector, and the possibility of patients of poor socio-economic status having more complications, needs investigation before firm conclusions can be made.

Cataract surgical services were accessed by most of the subjects via public health services despite there being 
a private hospital within easy access of the study area; this is a consequence of the socio-economic status of the population and the unaffordability of private services by this population and is reflective of the broader reality of South Africa where a majority of people do not have access to medical insurance (less than $15 \%$ of the South African population are members of private sector medical schemes). ${ }^{32}$

Approximately $50 \%$ of bilateral vision impairment in the sample resulted from uncorrected refractive error. This finding suggests that present systems need to be augmented to address the refractive error services and particularly the affordability of spectacles for the community, as many optometry practices exist in the study area but are not accessed by the community. According to $\mathrm{Vu}$ et al., ${ }^{33}$ individuals with uncorrected refractive error experience decreased vision-related quality of life and display increasing difficulty in performing vision-related tasks. The programme of South Africa's national Department of Health to employ optometrists in the public sector will address this challenge as, over the past several years, increasingly more optometry posts have been created in the public sector. Clinics within the public sector also source affordable spectacles to ensure that affordable options are available to patients.

\section{Conclusion}

The prevalence of blindness and vision impairment was considerably lower in the study sample, than the estimates suggested by the WHO. The primary cause of blindness and severe vision impairment was cataract, and uncorrected refractive error was the major cause of moderate vision impairment. The impact of blindness and vision impairment in the community should not be underestimated because, in many scenarios, communities such as that investigated do not have appropriate or adequate human resources, and a backlog of services can easily develop. Furthermore, health promotion efforts need to be undertaken to improve knowledge and uptake of services.

\section{Acknowledgement}

We thank PINK area-based management for facilitating access of the research teams to communities.

\section{Competing interests}

The authors declare that they have no financial or personal relationships which may have inappropriately influenced them in writing this article.

\section{Authors' contributions}

P.G. (Brien Holden Vision Institute) was the lead author on the paper and wrote the first draft. All other authors contributed significantly to the editing of this draft to bring the paper to completion.

\section{References}

1. Pascolini D, MariottiSP. Global estimates of visualimpairment:2010. BrJOphthalmol. 2012;96:614-618. http://dx.doi.org/10.1136/bjophthalmol-2011-300539

2. World Health Organization. Cumulative official updates to ICD-10 [homepage on the Internet]. [cited 07 February 2011]. Available from: http://www.who. int/classifications/icd/updates/Official_WHO_updates_combined_1996_2012 int/classifications

3. World Health Organization. Regional Health Observatory - Sub Regional Codelist. [homepage on the Internet]. [cited 25 November 2014]. Available from: http:// apps.who.int/gho/athena/data/download.xsl?format=xml\&target=SUBREGION\& profile=excel\&filter=

4. Resnikoff S, Pascolini D, Etya'ale $D$, et al. Global data on visual impairment in the year 2002. Bull World Health Organ. 2004;82:844-851.

5. International Centre for Eye Health. RAAB Instruction Manual. London: London School of Hygiene and Tropical Medicine; 2007.

6. Müller A, Zerom M, Limburg $\mathrm{H}$, et al. Results of a rapid assessment of avoidable blindness (RAAB) in Eritrea. Ophthalmic Epidemiol. 2011;18:103-108. http:// dx.doi.org/10.3109/09286586.2010.545932

7. Oye J, Kuper H. Prevalence and causes of blindness and visual impairment in Limbe urban area, South West Province, Cameroon. Br J Ophthalmol. 2007;91:14351439. http://dx.doi.org/10.1136/bjo.2007.115840

8. Kalua $K$, Lindfield R, Mtupanyama M, Mtumodzi D, Msiska V. Findings from a rapid assessment of avoidable blindness (RAAB) in Southern Malawi. PloS One. 2011;6:e19226. http://dx.doi.org/10.1371/journal.pone.0019226

9. Oye J, Kuper H, Dineen B, Befidi-Mengue R, Foster A. Prevalence and causes of blindness and visual impairment in Muyuka: A rural health district in South West Province, Cameroon. Br J Ophthalmol. 2006;90(5):538-542. http://dx.doi. org $/ 10.1136 /$ bjo.2005.082271
W

10. Wadud Z, Kuper H, Polack S, et al. Rapid assessment of avoidable blindness and needs assessment of cataract surgical services in Satkhira District, Bangladesh. Br J Ophthalmol. 2006;90:1225-1229. http://dx.doi.org/10.1136/bjo.2006.101287

11. Chiang $F$, Kuper $H$, Lindfield $R$, et al. Rapid assessment of avoidable blindness in the Occupied Palestinian Territories. PloS One. 2010;5:e11854. http://dx.doi. org/10.1371/journal.pone.0011854

12. Neena J, Rachel J, Praveen V, Murthy GV. Rapid assessment of avoidable blindness in India. PloS One. 2008;3:e2867. http://dx.doi.org/10.1371/journal. pone.0002867

13. Wu M. Rapid assessment of avoidable blindness in Kunming, China. Comm Eye Health/Int Cent Eye Health. 2007;20:10.

14. Statistics South Africa. Mid-year population estimates. July 2011. [homepage on the Internet]. [cited 31 July 2011]. Available from: http://www.statssa.gov.za/ publications/P0302/P03022011.pdf

15. Gaede B, McKerrow N. Outreach programme: Consultants visits to rural hospitals. Continuing Medical Education. 2011;29:54-58.

16. Naidoo KS, Raghunandan A, Mashige KP, et al. Refractive error and visual impairment in African children in South Africa. Invest Ophthalmol Vis Sci. 2003;44:3764-3770. http://dx.doi.org/10.1167/iovs.03-0283

17. Naidoo KS, Jaggernath J, Martin C, et al. Prevalence of presbyopia and spectacle coverage in an African population in Durban, South Africa. Optom Vis Sci. 2013;90:1424-1429. http://dx.doi.org/10.1097/OPX.0000000000000096

18. Mashige KP, Martin C, Cassim B, Ramklass S, Esterhuizen TM. Utilization of eye care services by elderly persons in the northern Ethekwini district of KwaZuluNatal province, South Africa. S Afr Optom. 2011;70(4):175-181.

19. Habiyakire $C$, Kabona $G$, Courtright $P$, Lewallen $S$. Rapid assessment of avoidable blindness and cataract surgical services in Kilimanjaro region, Tanzania. Ophthalmic Epidemiol. 2010;17:90-94. http://dx.doi.org/10.3109/09286580903453514

20. Mathenge W, Nkurikiye J, Limburg H, Kuper H. Rapid assessment of avoidable blindness in western Rwanda: Blindness in a postconflict setting. PLoS Med. 2007;4:e217. http://dx.doi.org/10.1371/journal.pmed.0040217

21. Kandeke L, Mathenge W, Giramahoro C, et al. Rapid assessment of avoidable blindness in two northern provinces of Burundi without eye services. Ophthalmic Epidemiol. 2012;19:211-215. http://dx.doi.org/10.3109/09286586. 2012.690493

22. Mathenge $\mathrm{W}$, Kuper $\mathrm{H}$, Limburg $\mathrm{H}$, et al. Rapid assessment of avoidable blindness in Nakuru district, Kenya. Ophthalmol. 2007;114:599-605. http://dx.doi. org/10.1016/j.ophtha.2006.06.057

23. Lindfield R, Griffiths U, Bozzani F, Mumba M, Munsanje J. A rapid assessment of avoidable blindness in Southern Zambia. PloS One. 2012;7:e38483. http://dx.doi. org/10.1371/journal.pone.0038483

24. Taylor HR, Pezzullo ML, Keeffe JE. The economic impact and cost of visual impairment in Australia. Br J Ophthalmol. 2006;90(3):272-275. http://dx.doi. org/10.1136/bjo.2005.080986

25. Kuper H, Polack S, Mathenge W, et al. Does cataract surgery alleviate poverty? Evidence from a multi-centre intervention study conducted in Kenya, the Philippines and Bangladesh. PLoS One. 2010;5(11):e15431. http://dx.doi. org/10.1371/journal.pone.0015431

26. Resnikoff S, Pascolini D, Mariotti SP, Pokharel GP. Global magnitude of visual impairment caused by uncorrected refractive errors in 2004. Bull World Health Organ. 2008;86:63-70. http://dx.doi.org/10.2471/BLT.07.041210

27. Abou-Gareeb I, Lewallen S, Bassett K, Courtright P. Gender and blindness: A meta-analysis of population-based prevalence surveys. Ophthalmic Epidemiol. 2001;8:39-56. http://dx.doi.org/10.1076/opep.8.1.39.1540 
28. Saw SM, Husain R, Gazzard GM, Koh D, Widjaja D, Tan DT. Causes of low vision and blindness in rural Indonesia. Br J Ophthalmol. 2003;87:1075-1078. http://dx.doi. org/10.1136/bjo.87.9.1075

29. Klein BE, Hubbard L, Ferrier NJ, et al. Detecting progression of nuclear sclerosis by using human grading versus semiautomated computer grading. Invest Ophthalmo Vis Sci. 2005;46:1155-1162. http://dx.doi.org/10.1167/iovs.04-0239

30. Naidoo K. Poverty and blindness in Africa. Clin Exp Optom. 2007;6:415-421. http://dx.doi.org/10.1111/j.1444-0938.2007.00197.x
31. Tabin G, Chen M, Espandar L. Cataract surgery for the developing world. Curr Opin Ophthalmol. 2008;19:55-59. http://dx.doi.org/10.1097/ICU.0b013e3282f154bd

32. Coovadia H, Jewkes R, Barron P, Sanders D, McIntyre D. The health and health system of South Africa: Historical roots of current public health challenges. Lancet. 374;817-834. http://dx.doi.org/10.1016/S0140-6736(09)60951-X

33. Vu H, Keefe J, McCarty C, Taylor H. Impact of unilateral and bilateral vision loss on quality of life. Br J Ophthalmol. 2005;89:360-363. http://dx.doi.org/10.1136/ bjo.2004.047498 